\title{
Biomechanical Properties of Bovine Claw Horn
}

\author{
A. Franck ${ }^{1}$; G. Cocquyt ${ }^{2} ;$ P. Simoens ${ }^{2} ;$ N. De Belie ${ }^{1}$ \\ ${ }^{1}$ Magnel Laboratory for Concrete Research, Department of Structural Engineering, Faculty of Engineering, \\ Ghent University, Technologiepark-Zwijnaarde 904, B-9052 Gent, Belgium e-mail of corresponding author: \\ Arnold.Franck@UGent.be \\ ${ }^{2}$ Department of Morphology, Faculty of Veterinary Medicine, Ghent University, Salisburylaan 133, B-9820 \\ Merelbeke, Belgium, e-mail: Paul.Simoens@UGent.be
}




\section{Abstract}

Inadequate properties of concrete floors in cattle houses seem to be the primary cause of most claw problems, resulting in economic losses and impaired animal welfare. Many claw diseases are sequels of an extreme local overload. In this paper, the mechanical strength of bovine claw horn is studied.

The average Young's modulus $E$ determined in bending and compression using a test velocity of $1 \mathrm{~mm} / \mathrm{min}$ was $382 \mathrm{MPa}$ for horn from the dorsal wall of the bovine claw, $261 \mathrm{MPa}$ for horn from the abaxial wall and 13.6 MPa for bulb horn. There is a significant difference in Young's modulus, hence in stiffness, between dorsal and abaxial wall horn. The average yield stress was 14.3 MPa for dorsal wall horn and 10.7 MPa for abaxial wall horn in a three-point bending test, and 56.0 MPa for bulb horn in a compression test on samples with $100 \mathrm{~mm}^{2}$ surface area and $4 \mathrm{~mm}$ height. The registered average Poisson's ratio ? was 0.38. Histological observations could not explain the biomechanical differences between the dorsal and abaxial wall horn. The number of horn tubules per $\mathrm{mm}^{2}$ was smaller and the diameter of the tubules larger in bulb horn than in wall horn.

In future research, the yield stress of the horn will be related with the maximum pressures that can occur between cattle claw and concrete floor.

\section{Keywords}

bovine claw, keratin, concrete floor, Young's modulus, Poisson's ratio 


\section{Notation}

E Young's modulus, MPa

$N \quad$ number of samples

a probability

e strain

? Poisson's ratio

s $\quad$ stress, $\mathrm{MPa}$

\section{Introduction}

In modern farms cattle are almost uniquely housed on full concrete floors or on pre-fabricated slatted concrete floors. Despite the many advantages of concrete floors, animals often show claw diseases which are the direct and indirect effects of the roughness and slipperiness of the floor (McDaniel \& Wilk, 1991). Many claw diseases are caused by traumata of the dermis of the sole, which are sequels of an extreme local overload (Distl \& Mair, 1993). Lameness in cattle is widely recognised as a major economic and welfare problem (Vermunt \& Greenough, 1996).

In this paper, the determination of the biomechanical properties of bovine claw horn is presented. These properties are related with the architecture of the wall and bulb horn, i.e. the arrangement and spatial relationship of tubular, intertubular and laminar horn cells. 
The support and load bearing function of the bovine claw is provided by the epidermal claw wall (mainly its abaxial portion) and partly by the bulbar part of the sole (Toussaint Raven et al., 1977). This is especially the case on hard floor surfaces because, due to the axial inclination of the sole, only the abaxial claw wall margin (solear margin) is in contact with the substrate. On a soft soil, the sole will contribute more to the load bearing function.

As in most biological tissues, the equine hoof wall material is morphologically nonhomogeneous and mechanically orthotropic. In horses' hooves there are differences in biomechanical properties between inner and outer wall segments because of the difference in histological and cytological organisation of the stratum medium and the regional differences in water content (Leach \& Zoerb, 1983). Similar differences can also be expected in bovine claws. No significant differences in tensile forces on the nails that fixate the horseshoe could be found between black and white horse hooves (Runciman et al., 2004), hence no differences in mechanical strength between dark and light bovine claws are expected.

It has previously been proven that floor surface roughness has a profound effect on the clawfloor contact area, average contact pressure and maximum local contact pressure (De Belie \& Rombaut, 2003). This study should contribute to better designed floors and improved animal welfare and economy.

\section{Materials and methods}

\subsection{Horn samples}


The biomechanical properties of 46 samples of claw horn from 16 cattle were tested. The data registered for all samples are summarised in Table 1 . The mean weight of the samples was $3.049 \mathrm{~g}$ for dorsal and abaxial samples and $0.470 \mathrm{~g}$ for bulb samples. The mean age of the cows the samples were taken from was 37.9 months and the mean weight was $671 \mathrm{~kg}$.

A three-point bending test was used to examine 36 samples of wall horn ( 21 dorsal and 15 abaxial), and 10 samples of bulb horn were submitted to a compression test. No axial wall samples were submitted to bending tests because the horn wall in this area was not high enough to make a sample with sufficient length. The choice of the tests reflects the way the claws are loaded in living animals.

The horn samples were cut from the claws of freshly slaughtered cows by means of an oscillating saw (Figs 1 and 2). The underlying soft dermal structures were removed immediately.

The horn samples were stored in small sealed plastic containers to prevent dehydration. The samples were then kept at $7^{\circ} \mathrm{C}$ until further refinement with a planing machine (with a slowly moving chisel). This equipment was used to make a sample with smooth, parallel surfaces and with precise dimensions (deviations of $0.1 \mathrm{~mm}$ only). This procedure was requisite because all samples needed to have the same cross section for bending tests and the same surface area for compression tests.

The dorsal and abaxial wall samples for the bending tests were $10 \mathrm{~mm}$ broad, $4 \mathrm{~mm}$ thick and the length ranged between 45 and $60 \mathrm{~mm}$, exceeding the $40 \mathrm{~mm}$ span between the supports of the test machine. In the samples, the horn tubules were parallel with the length axis of the 
sample. In order to comply with the theory of pure elastic bending (Lloyd Instruments, 2000), it was necessary that the span was 10 times the thickness of the horn specimens. The bulb samples for compression tests had dimensions of $10 \mathrm{~mm}$ in length by $10 \mathrm{~mm}$ in width by 4 $\mathrm{mm}$ in thickness. Once refined, the horn samples were weighed and subsequently tested.

\subsection{Modulus of elasticity}

The most direct way to determine the (bio)mechanical properties of the claw horn is the determination of Young's modulus $E$ (modulus of elasticity), which is a measure of the rigidity and the stiffness of the horn. The modulus of elasticity is the ratio of stress to strain on the loading plane along the loading direction:

$$
E=\frac{\sigma}{\varepsilon}
$$

Where: $E$ is Young's modulus in MPa; $s$ is the stress in MPa; and $e$ is the strain which is the elongation or contraction of the sample, divided by its original length.

In contrast to the elasticity, the stiffness of the horn is a measure for the ability of the claw to resist deformation during floor contact (distribution of peak contact pressures) and for the sensitivity to claw lesions.

Young's modulus was determined with a texture analyser (TA500 Texture Analyser, Lloyd Instruments, Fareham, UK). The maximum load was $500 \mathrm{~N}$. The three-point bending test is illustrated in Fig. 3. In this test the wall horn samples can be seen as small beams which were laid on two supports, separated from each other with a span of $40 \mathrm{~mm}$. The load was exerted on the horn 'beam', exactly in the middle of the span (for bulbar samples a simple compression test was used). Each sample was tested with loading velocities of $1 \mathrm{~mm} / \mathrm{min}$ and $15 \mathrm{~mm} / \mathrm{min}$ in order to assess the particular visco-elastic properties of claw horn which 
consists of the composite keratin substance and moisture. The time between the experiments at the two test velocities ranged from 20 min to 2 hours, allowing enough time for the samples to regain their original state.

The texture analyser provided the necessary input for generating the force-deformation curve. The deformation was the lowering of the knife-edge which caused the horn beam to bend and the load was registered with a force transducer (load cell). Force and deformation were provided in electronic (ASCII) format, which could be converted to MS-Excel format through NEXYGEN (Lloyd Instruments, Fareham, UK), the proprietary software that was delivered with the texture analyser. The force-deformation curve could then easily be converted to a stress-strain diagram. The maximum bending stress was also registered by the texture analyser. This stress was found in fibre(s) furthest away from the neutral axis in the plane of curvature. The dimensions of the sample had to be entered in the software prior to calculation.

The modulus of elasticity is determined as the slope of the initial straight line portion of the stress-strain curve. Young's modulus was retrieved manually by drawing a tangent line on the initial slope of the curve of every sample (Fig. 4, line 'a'). The points of the curve that coincide with the tangent line were represented graphically; the slope of that graph was then calculated by MS-Excel (linear regression). Sometimes the curves showed a convex course at the origin (Fig. 6, arrow), probably due to the initial bending of some samples. This convex course was not taken into account when Young's modulus was determined.

The modulus of elasticity was determined for all samples and was rounded to three significant digits. 


\subsection{Yield stress}

For a truly elastic material under uniaxial tensile or compressive load, the coordinate on a stress-strain curve at which the stress begins to vary in a nonlinear manner with the corresponding strain, is the proportional limit. The stress and strain values at this point are known as the proportional limit stress and the proportional limit strain, respectively. At this point the material starts to loose its mechanical function (not capable any more of withstanding loads exerted on the material) and begins to loose its resistance to further loading because the material properties change. This beginning of the yield region is generally agreed to be that point where the $a$-helical arrangement of the keratin microfibrils breaks down (Leach \& Zoerb, 1983).

The yield stress of the samples that had undergone the three-point bending test was derived from the stress-strain diagrams. The proportional limit is the point on the force-deformation (or stress-strain) curve where the line becomes nonlinear.

As it is sometimes difficult to determine precisely where the stress-strain curve becomes nonlinear, a convention was used for all samples. A line with the same slope as the initial straight line portion of the stress-strain curve (i.e. parallel to the line representing the modulus of elasticity) was drawn through the point with strain equal to $1 \%$ (Fig. 4, line 'b'). The intersection between that line and the stress-strain diagram indicated the yield stress.

The yield stress of eight samples from the bulbar area was determined with a hydraulic compression machine (Amsler FM 2750, Roell + Korthaus, Schaffhausen, Switzerland). The samples were compressed between two flat plates; the distance between the plates and the compression force was recorded electronically. This compression test was done with another device than the texture analyser because the force limit of the texture analyser $(500 \mathrm{~N})$ is 
below the yield point of the sample. The bulb samples were already used for determining Young's modulus but they could be tested again since they had only undergone elastic deformation (Leach \& Zoerb, 1983).

\subsection{Poisson's ratio}

The Poisson's ratio ? was determined for five samples of the abaxial and dorsal horn wall by means of a tensile test in the direction of the tubules using a universal testing machine (Instron 4501, Instron Corp., Canton, USA). The Poisson's ratio is the transverse contraction to longitudinal elongation in the direction of the stretching force.

New samples were used for the tensile test; the samples were shaped in the form of a small balancer (narrower in the middle). The width was $5 \mathrm{~mm}$ and the length was $10 \mathrm{~mm}$.

Other data were also recorded during this test. The strain at rupture is defined as the elongation of the sample (which was measured with an extensometer), divided by its original length, at the moment the sample breaks. The tensile strength is the stress of the sample submitted to the test at the moment the sample breaks. The tensile strength was determined by dividing the applied force by the contracted section (which was measured).

\subsection{Moisture content}

After testing, the samples were dried completely in an oven at $105^{\circ} \mathrm{C}$ until their mass was constant. The moisture content was calculated as the difference between oven-dry and initial mass, divided by the dry mass.

\subsection{Histology}


Tissue samples $(5 \mathrm{~mm} \times 5 \mathrm{~mm} \times 10 \mathrm{~mm})$ were taken from the dorsal (11 samples), abaxial (14 samples) and bulbar (10 samples) zone of the lateral claw of the right forelimb of 15 cows. They were fixed in formaldehyde $3.5 \%$ for 1 week, processed by routine histological methods and embedded in paraffin wax. The cutting surface, perpendicular to the long axis of the tubules, was softened in $\mathrm{HCl} 5 \%$ for at least 3 days. Sections of $5 \mu \mathrm{m}$ thick were cut and stained with eosin and haematoxylin. The width of the dorsal and abaxial claw horn was measured using a motorised microscope (Olympus BX61, Olympus Belgium, Aartselaar, Belgium) and computer assisted morphometry (AnalySIS 3.2, Olympus Belgium). In all samples the number of tubules per $\mathrm{mm}^{2}$ was counted and the largest and smallest diameter of the tubules noted.

\section{Results}

\subsection{Modulus of elasticity}

The results of the bending and compression tests are summarised in Table 2.

The values for the two bending test velocities are significantly different (probability of 0.05). The test velocity of $15 \mathrm{~mm} / \mathrm{min}$ results in a Young's modulus that is on average $9.2 \%$ (dorsal) and $11.2 \%$ (abaxial) larger than when using a test velocity of $1 \mathrm{~mm} / \mathrm{min}$.

A typical stress-strain diagram resulting from the bending test is shown in Fig. 4. All samples had similar curve shapes, only the slopes were different. 
The stress-strain diagrams of the compression tests showed only the initial straight part of the curve in Fig. 4. This was because the limit of the texture analyser $(500 \mathrm{~N})$ was reached well before the yield point of the sample was reached.

The Kolmogorov-Smirnov test proved that the results of the bending and compression test were normally distributed. Analysis of variance for the bending test results showed that parameters such as age of the animal, living bodyweight, gender, type of animal (beef or dairy cattle), medial a lateral claw, fore or hind limb and right or left limb did not have any significant influence $(a=0.05)$ on Young's modulus. In contrast, significant differences $(a=$ 0.05) were found between the modulus of elasticity of dorsal and abaxial wall horn (Fig. 5).

\subsection{Yield stress and Poisson's ratio}

A typical stress-strain diagram for the compression tests on the bulb horn is shown in Fig. 6 . The graph indicates that there is a lot of plastic deformation (distance between point ' $a$ ' and 'b’).

The yield stress of wall samples resulted in $14.3 \pm 3.3 \mathrm{MPa}$ (minimum of 7.4 MPa; maximum of 19.4 MPa) for the dorsal wall and in $10.7 \pm 4.5 \mathrm{MPa}$ (minimum of 7.2 $\mathrm{MPa}$; maximum of 25.4 MPa) for the abaxial wall, both at a test velocity of $1 \mathrm{~mm} / \mathrm{min}$. The yield stress of bulb samples (number of samples $=8$ ) resulted in $56.0 \pm 12.0 \mathrm{MPa}$ (minimum of $38.0 \mathrm{MPa}$; maximum of 71.0 MPa).

The correlation between Young's modulus and the yield point of the same samples was 0.197 . 
The values for Poisson's ratio, determined with the tensile test, are summarised in Table 3.

\subsection{Moisture content}

The average moisture content of all samples $(\mathrm{N}=46)$ amounted to $0.299 \pm 0.024$ (minimum of 0.253 ; maximum of 0.348 ). No significant differences for moisture content between the different locations of the claw were found $(a=0.05)($ Fig. 7).

\subsection{Histology}

In the horn of the dorsal and abaxial wall, three zones covering the parietal lamellar zone could be distinguished, viz., a superficial zone with flattened tubules (Fig. 8, zone 'A'), an intermediate zone with round to oval tubules (Fig. 8, zone 'B') and a deep zone without tubules (Fig. 8, zone 'C'). In some cases, however, the deep zone ' $\mathrm{C}$ ' contained few large tubules with a thin cortex embedded in incompletely keratinised intertubular cells. In zones ' $\mathrm{A}$ ' and ' $\mathrm{B}$ ' the largest diameter of the tubules was orientated parallel to the outer surface of the claw wall and the smallest diameter was orientated perpendicular to the latter. The mean thickness of the claw horn was $4292.71 \pm 1006.18 \mu \mathrm{m}$ for the dorsal wall and $4683.40 \pm$ $1427.19 \mu \mathrm{m}$ for the abaxial wall. The wall thickness nor the number and diameter of the tubules in zones 'A' and 'B' were significantly different $(a=0.05)$ in the dorsal and abaxial wall (Table 4).

Histology of the bulbar horn revealed a tubular arrangement in all samples but one (Fig. 9). In cross-section the horn tubules had a round to oval shape. The cortex of the tubules was not easy to distinguish from the intertubular horn and consisted of keratinised cells which were orientated in a concentric pattern around the lumen. Most tubules had a single lumen but tubules with 2 till 4 lumina were also noticed. The tubules were separated by a large amount 
of intertubular horn consisting of voluminous keratinised cells. The numerical density of the tubules in the bulb horn was lower than in the wall horn (Table 4). Mean values of the largest and smallest tubular diameters were higher in bulb horn than in wall horn, but a significant difference was only noticed between the largest diameter of the tubules of the bulb and those of zone ' $\mathrm{B}$ ' of the abaxial horn, and between the smallest diameter of the tubules of the bulb and those of zone 'A' from the wall horn.

\section{Discussion}

It must be emphasised that Young's modulus derived from compression tests cannot be compared directly with Young's modulus derived from bending tests for this orthotropic material. This is due to the different nature of bending tests and compression tests. Furthermore, the dimensions of the samples play an important role and have an effect on Young's modulus. Owing to the morphological restriction, the compression tests were done with samples with a very small thickness compared with their width and length. Normally, for most materials (e.g. concrete, steel ...), Young's modulus is derived from samples with a higher height/width ratio. Conversion formulae to compare tests on samples with different dimensions do not exist for biomaterials.

The values for Young's modulus found in the present study resemble those found in equine hoof horn. Literature mentions values derived from compression tests of approximately 377 MPa for vertically loaded ponies' hoof wall (Butler \& Hintz, 1977) and between 240 and 480 MPa for the equine hoof wall (Landeau et al., 1983), and values determined by tensile tests of 410 to $485 \mathrm{MPa}$ in dorsal hoof wall (Bertram \& Goseline, 1986). In the study of Hinterhofer et al. (1998), Young's modulus of physiologically moist equine hoof wall samples was $735 \pm$ 
289.5 MPa, sole samples had a value for the modulus $E$ of $230 \pm 92.4 \mathrm{MPa}$ and the testing of frog samples resulted in significantly lower values of $9.9 \pm 0.6 \mathrm{MPa}$. In contrast to the present study, there was no significant difference between Young's modulus of dorsal and lateral wall samples. In pigs, Webb et al. (1984) found that the average compressive strength of the dorsal claw wall $(14.5 \pm 0.7 \mathrm{MPa})$ was significantly larger than the strength of the horn from the mid-abaxial side wall $(10.6 \pm 0.5 \mathrm{MPa})$. This difference agrees with the results described in our paper. The ultimate compressive strength of pig claw wall was determined at $8 \mathrm{MPa}$ which also corresponds with the results in the present research.

The present findings contrast with data from a preliminary study on the bovine claw (Rombaut \& Simoens, 2002) in which the modulus of elasticity was determined to be 1.65 MPa for compression tests of bulb horn and $3597 \mathrm{MPa}$ for bending tests of wall horn (samples stored under $60 \%$ relative humidity and test velocity of $1 \mathrm{~mm} / \mathrm{min}$ ). These results differ from the results in the present study with an order of magnitude equal to 10 . This is probably due to the fact that the samples in the preliminary study had a different shape, a smaller size and were not refined with a planing machine, but were rather roughly cut with a saw.

The fact that no significant differences for parameters other than the location of the horn were found in the present study may be due to the unequal distribution in gender $(17.4 \%$ male, $82.6 \%$ female) and constitution ( $89.2 \%$ beef, $4.3 \%$ dairy and $6.5 \%$ mixed) of the animals examined.

The differences between Young's modulus at different test velocities confirm the visco-elastic behaviour of claw horn. 
The difference in yield stress between wall and bulb horn samples can again be explained by the different nature of bending tests and compression tests. The value of Poisson's ratio for keratin, the main constituent of horn, which was determined in the present study corresponds with the data described by Vincent (1982), who found that the Poisson's ratio for keratin ranges between 0.35 and 0.9 .

Normally the moisture content of visco-elastic materials plays an important role in the mechanical strength of the material, but since the variance in moisture content of all samples was very small, no significant effect was found.

The microscopical architecture of the bovine claw wall is similar to that of the equine hoof (Leach \& Zoerb, 1983), except for the presence of cylindrical horn tubules which are present in the inner third of the equine hoof wall but were observed only in a few cases in the present study.

The significant difference in biomechanical properties between the dorsal and abaxial wall horn can not be explained by the minor differences in wall thickness, nor by the tubular numerical density or diameter of the horn tubules of both wall segments. The difference in elasticity and stiffness between wall horn and bulb horn can be related to the lower density and the larger diameter of tubules in the bulb horn.

\section{Conclusion}


The resistance to deformation of claw horn is about 1000 times lower than for steel and about 150 times lower than for concrete. Although they cannot be compared directly, the values for the compression tests are 19 to 28 times lower than the values for the bending tests (same test velocity). Bulb horn is a lot more elastic than wall horn, and dorsal wall horn is stiffer than abaxial wall horn. No other parameters had an influence on Young's modulus of the horn of the bovine claws.

The values for Young's modulus found in this study of bovine claw horn correspond with the values found in equine hoof horn.

The tests conducted on the horn samples show that the horn is indeed a visco-elastic material. 


\section{Acknowledgements}

The authors would like to thank the Special Research Fund (BOF) of Ghent University for the funding of this research (project number: 01113203 and 011B4101). The Faculty of Bioscience Engineering of Ghent University and the Belgian Research Centre for Pipes and Fittings (BECETEL) are thanked for their contributions and support. L. De Bels is greatly acknowledged for her technical support. 


\section{References}

Bertram J; Goseline J (1986). Fracture toughness design in horses hoof keratin. Journal of Experimental Biology, 125, 29-47

Butler K; Hintz H (1977). Effect of level of feed intake and gelatine supplementation on growth and quality of hoofs of ponies. Journal of Animal Science, 44, 257-261

De Belie N; Rombaut E (2003). Characterisation of claw-floor contact pressures for standing cattle and the dependency on concrete roughness. Biosystems Engineering, 85(3), 339346

Distl O; Mair A (1993). Computerized analysis of pedobarometric forces in cattle at the ground surface/floor interface. Computers and Electronics in Agriculture, 8, 237-250

Hinterhofer C; Stanek C; Binder K (1998). Elastic modulus of equine hoof horn, tested in wall samples, sole samples and frog samples at varying levels of moisture. Berliner und Münchener Tierärtzliche Wochenschrift, 111, 217-221

Landeau J; Barret D; Battermann S (1983). Mechanical properties of the equine hooves. American Journal of Veterinary Research, 44, 100-102

Leach D; Zoerb G (1983). Mechanical properties of equine hoof wall tissue. American Journal Veterinary Research, 44(11), 2190-2194

Lloyd Instruments Ltd. (2000). Batch testing utility V2.0 Issue 3 fr use with Nexygen V4.0. Technical support department, Fareham, UK

McDaniel B; Wilk J (1991). Lameness in dairy cows. In: Proceedings of the British Cattle Veterinary Association, 1990-1991, 66-80

Rombaut E; Simoens K (2002). Karakteriseren van het contact tussen een rundveehoef en de stalvloer. [Characterisation of the contact area between bovine claw and the animal house's concrete floor.] Master thesis, Universiteit Gent, Gent, Belgium 
Runciman R J; Thomason J J; Springett G; Bullock S; Sears W (2004). Horseshoe fixation versus hoof colour, a comparative study. Biosystems Engineering, 89(3), 377382

Toussaint Raven E; Haalstra R; Peterse D (1977). Klauwverzorging bij het Rund. [Cattle Foot Care.] De Uithof, Utrecht, The Netherlands

Vermunt J; Greenough P(1996). Claw conformation of dairy heifers in two management systems. British Veterinary Journal, 152, 321-331

Vincent J (1982). Structural Biomaterials. The MacMillan Press, London \& Basingstoke, UK

Webb N; Penny R; Johnston A (1984). Effect of a dietary supplement of biotin on pig hoof strength and hardness. The Veterinary Record, 114, 185-189 


\section{Figure captions}

Fig. 1. Cutting of the claw horn samples

Fig. 2. Locations where the horn samples were taken (a, dorsal wall; b, abaxial wall; $c$, bulb)

Fig. 3. Three-point bending test on wall horn sample by means of a texture analyser ( $a$, supports; $b$, sample; $c$, load)

Fig. 4. Stress-strain diagram of bending test of claw horn (Young's modulus $=402 \mathrm{MPa}$, yield stress $=16.4 \mathrm{MPa}$, test velocity $=1 \mathrm{~mm} / \mathrm{min}$ )

Fig. 5. Young's modulus for test velocities of $1 \mathrm{~mm} / \mathrm{min}$ (left) and $15 \mathrm{~mm} / \mathrm{min}$ (right), versus location of wall horn (error bars: 95\% confidence interval for mean values)

Fig. 6. Stress-strain diagram of bulb horn for loading and unloading (yield point $=47 \mathrm{MPa}$ ); note the slope (arrow) of the initial segment of the curve and its tangent line (' $a$ ')

Fig. 7. Moisture content in the various horn segments (error bars: $95 \%$ confidence interval for mean)

Fig. 8. Histological section of the abaxial claw wall (A, superficial zone with flattened tubules; $B$, intermediate zone with round to oval tubules; $C$, internal zone without tubules; $D$, parietal lamellar zone; , dermis; bar $=500 \mu \mathrm{m})$

Fig. 9. Histological section of the bulb horn perpendicular to the long axis of the horn tubule (a, large tubular diameter; $b$, small tubular diameter; bar $=100 \mu \mathrm{m})$ 


\section{Tables}

Table 1

Parameters registered for horn samples

\begin{tabular}{|c|c|}
\hline Parameter & Number of samples $(N)$ \\
\hline \multicolumn{2}{|l|}{ Type of bovine } \\
\hline Beef & 41 \\
\hline Dairy & 2 \\
\hline Unspecified & 3 \\
\hline \multicolumn{2}{|l|}{ Gender } \\
\hline Male & 8 \\
\hline Female & 38 \\
\hline \multicolumn{2}{|l|}{ Limb } \\
\hline Right fore & 11 \\
\hline Left fore & 11 \\
\hline Right hind & 5 \\
\hline Left hind & 11 \\
\hline Unspecified & 8 \\
\hline \multicolumn{2}{|l|}{$\overline{\text { Claw }}$} \\
\hline Medial & 19 \\
\hline Lateral & 19 \\
\hline Unspecified & 8 \\
\hline \multicolumn{2}{|l|}{ Location on claw } \\
\hline Dorsal wall & 21 \\
\hline Abaxial wall & 15 \\
\hline
\end{tabular}


Table 2

Young's modulus of bovine claw horn for different tests and test velocities

\begin{tabular}{|c|c|c|c|c|c|c|c|}
\hline \multirow[t]{2}{*}{ Test } & \multirow{2}{*}{$\begin{array}{l}\text { Velocity, } \\
\mathrm{mm} / \mathrm{min}\end{array}$} & & \multirow{2}{*}{$\begin{array}{l}\text { Number of } \\
\text { samples }(N)\end{array}$} & \multicolumn{4}{|c|}{ Young's modulus, $\mathrm{MPa}$} \\
\hline & & & & Mean & $S D$ & Minimum & Maximum \\
\hline \multirow{4}{*}{ Bending } & & $\begin{array}{c}\text { Dorsal } \\
\text { wall }\end{array}$ & 21 & 382 & 98 & 218 & 568 \\
\hline & & $\begin{array}{c}\text { Abaxial } \\
\text { wall }\end{array}$ & 15 & 261 & 109 & 146 & 607 \\
\hline & & $\begin{array}{l}\text { Dorsal } \\
\text { wall }\end{array}$ & 21 & 417 & 108 & 264 & 614 \\
\hline & & $\begin{array}{c}\text { Abaxial } \\
\text { wall }\end{array}$ & 15 & 291 & 105 & 179 & 609 \\
\hline Compression & 1 & $\begin{array}{l}\text { Sole } \\
\text { (bulb) }\end{array}$ & 10 & 13.6 & 1.68 & 11.5 & 16.3 \\
\hline
\end{tabular}

SD, standard deviation 
Table 3

Poisson's ratio, strain at rupture and tensile strength of claw wall horn

\begin{tabular}{lccccc}
\hline & $\begin{array}{c}\text { Number } \\
\text { of }\end{array}$ & Mean & Standard & Minimum & Maximum \\
& samples & & deviation & & \\
& $(N)$ & & & & \\
\hline Poisson's ratio & 5 & 0.38 & 0.02 & 0.36 & 0.40 \\
Strain at rupture, \% & 5 & 128 & 23 & 109 & 164 \\
Tensile strength, $\mathrm{MPa}$ & 5 & 16.2 & 5.0 & 8.3 & 22.2 \\
& & & & & \\
\hline
\end{tabular}




\section{Table 4}

Numerical density and diameters of the horn tubules of the bovine claw (mean values)

\begin{tabular}{lccc}
\hline \multicolumn{1}{c}{ Location } & Number of tubules, & \multicolumn{2}{c}{ Diameter of tubules, $\mu m$} \\
& $m^{-2}$ & Minimum & Maximum \\
\hline Dorsal wall - zone 'A' & $64.49 \pm 14.41$ & $12.17 \pm 2.85$ & $38.80 \pm 7.98$ \\
Dorsal wall - zone 'B' & $57.10 \pm 10.92$ & $26.22 \pm 16.41$ & $55.16 \pm 20.38$ \\
Abaxial wall - zone 'A' & $62.28 \pm 23.27$ & $12.61 \pm 3.00$ & $45.09 \pm 15.28$ \\
Abaxial wall - zone 'B' & $50.89 \pm 21.28$ & $23.20 \pm 7.98$ & $48.05 \pm 17.05$ \\
Sole (bulb) & $8.22 \pm 4.09$ & $39.21 \pm 21.50$ & $74.31 \pm 27.17$ \\
\hline
\end{tabular}


Figures

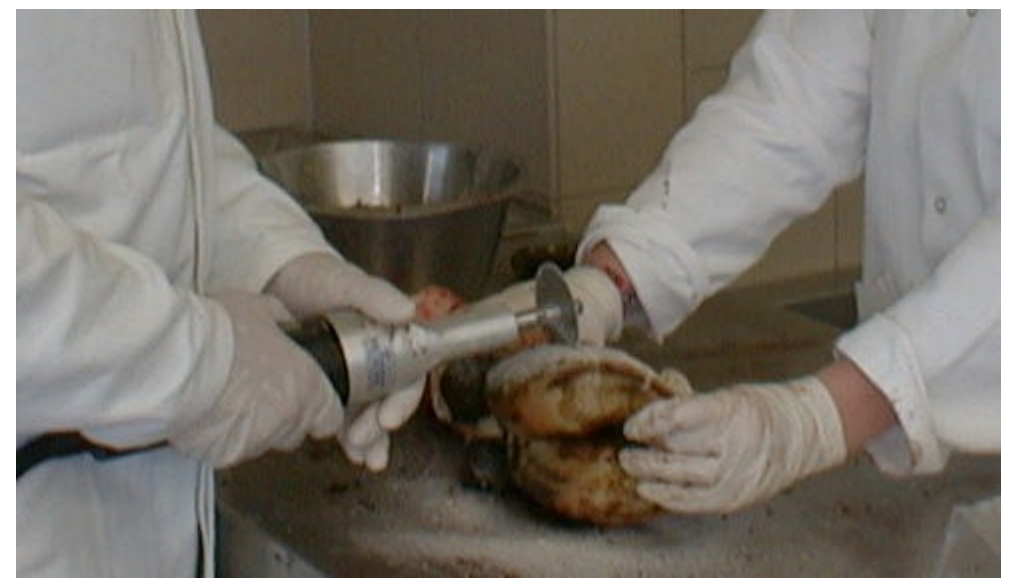

Fig. 1. Cutting of the claw horn samples 

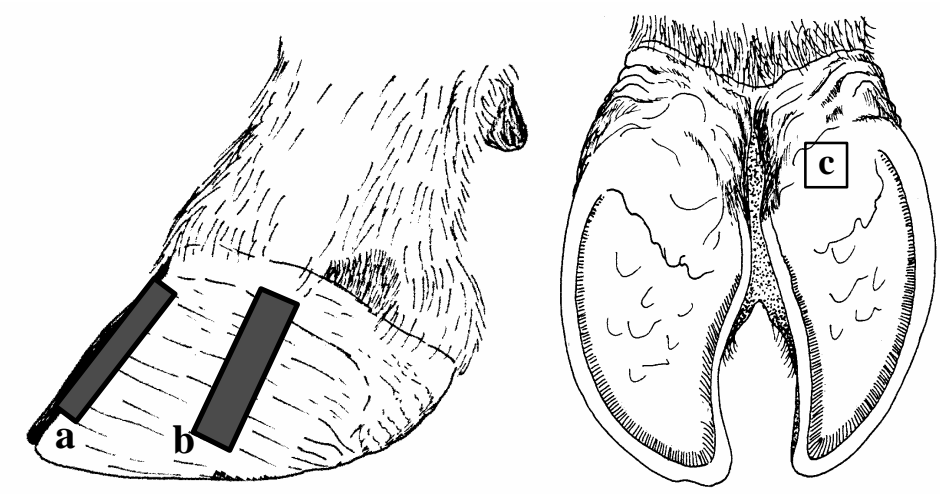

Fig. 2. Locations where the horn samples were taken (a, dorsal wall; b, abaxial wall; $c$, bulb) 


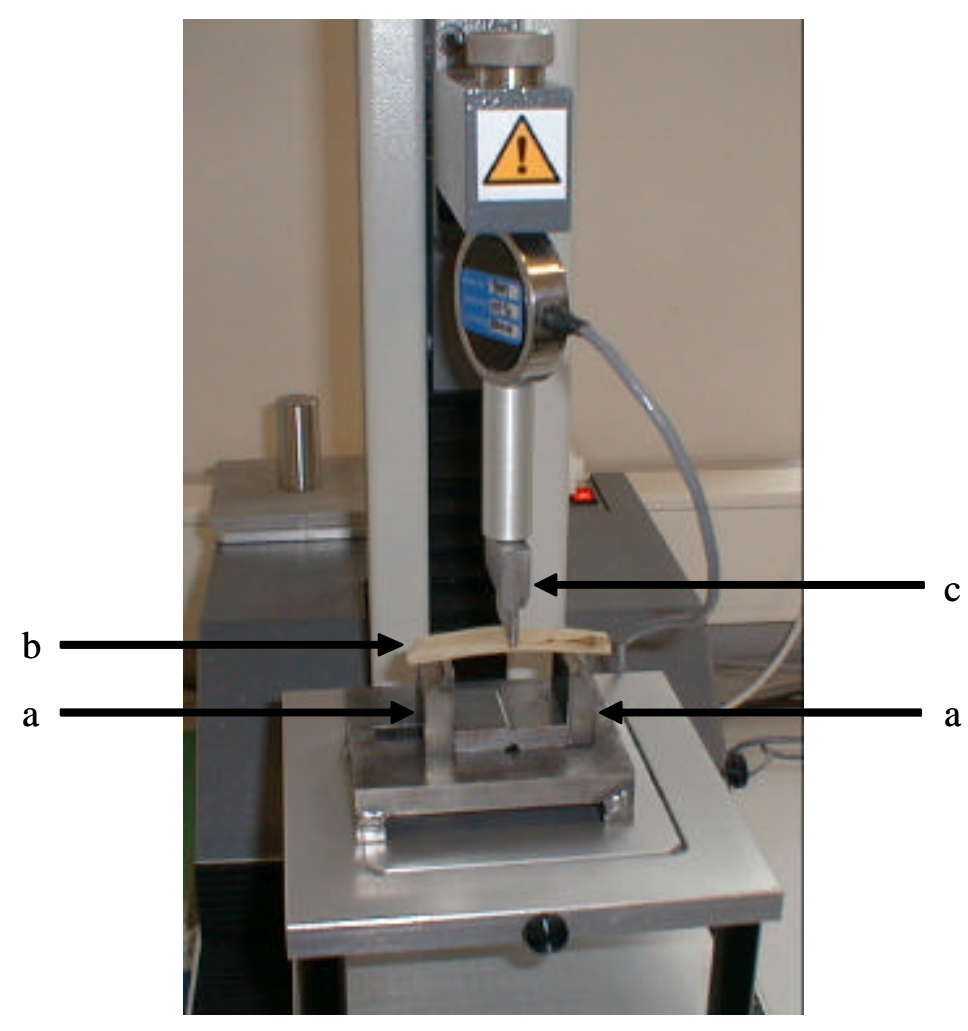

Fig. 3. Three-point bending test on wall horn sample by means of a texture analyser ( $a$, supports; $b$, sample; $c$, load) 


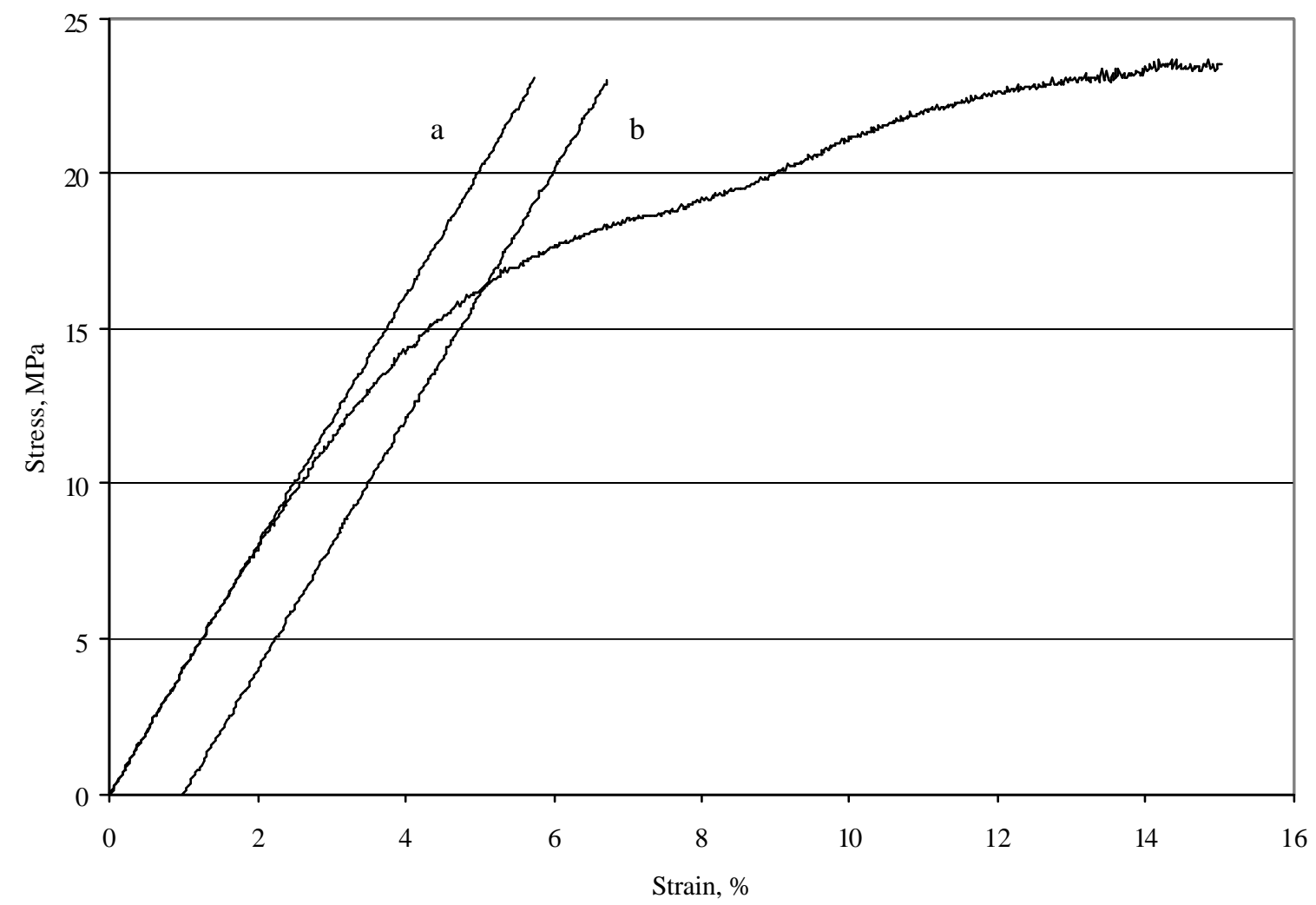

Fig. 4. Stress-strain diagram of bending test of claw horn (Young's modulus $=402 \mathrm{MPa}$, yield stress $=16.4 \mathrm{MPa}$, test velocity $=1 \mathrm{~mm} / \mathrm{min}$ ) 

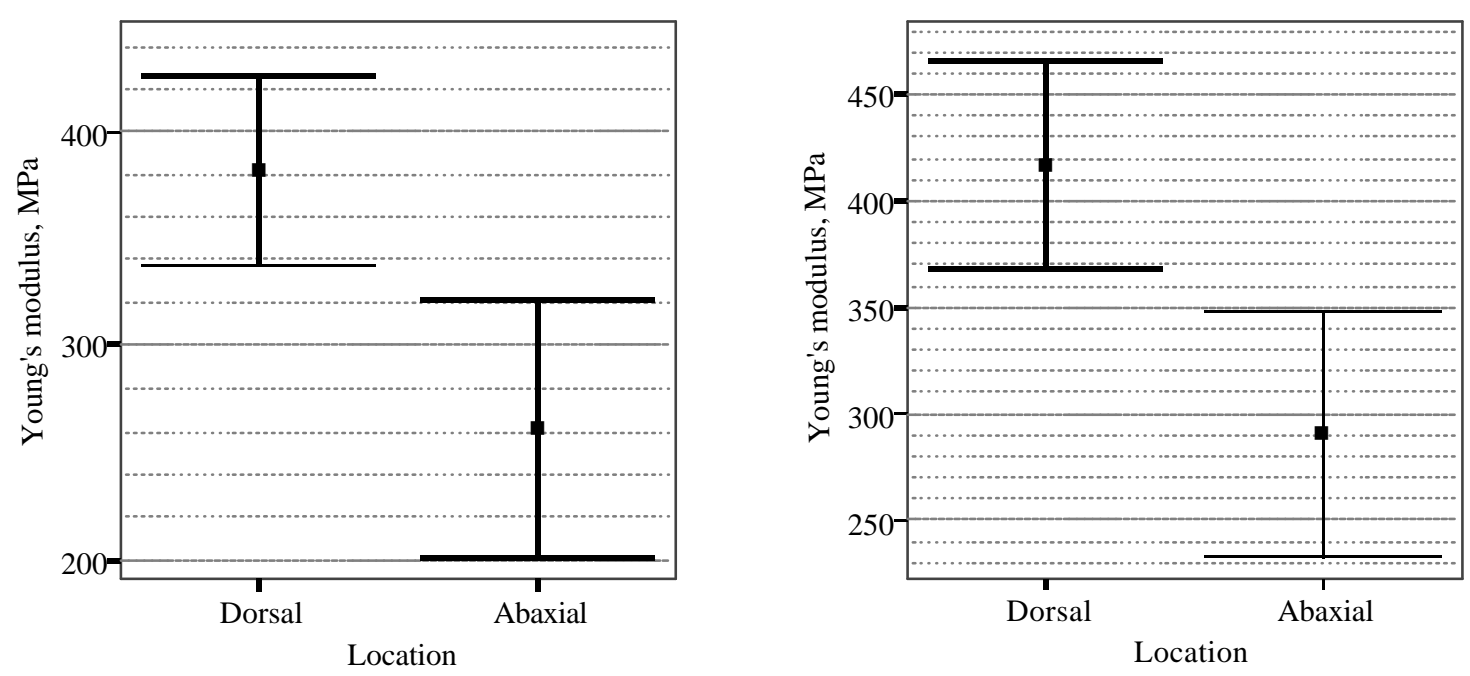

Fig. 5. Young's modulus for test velocities of $1 \mathrm{~mm} / \mathrm{min}$ (left) and $15 \mathrm{~mm} / \mathrm{min}$ (right), versus location of wall horn (error bars: 95\% confidence interval for mean values) 


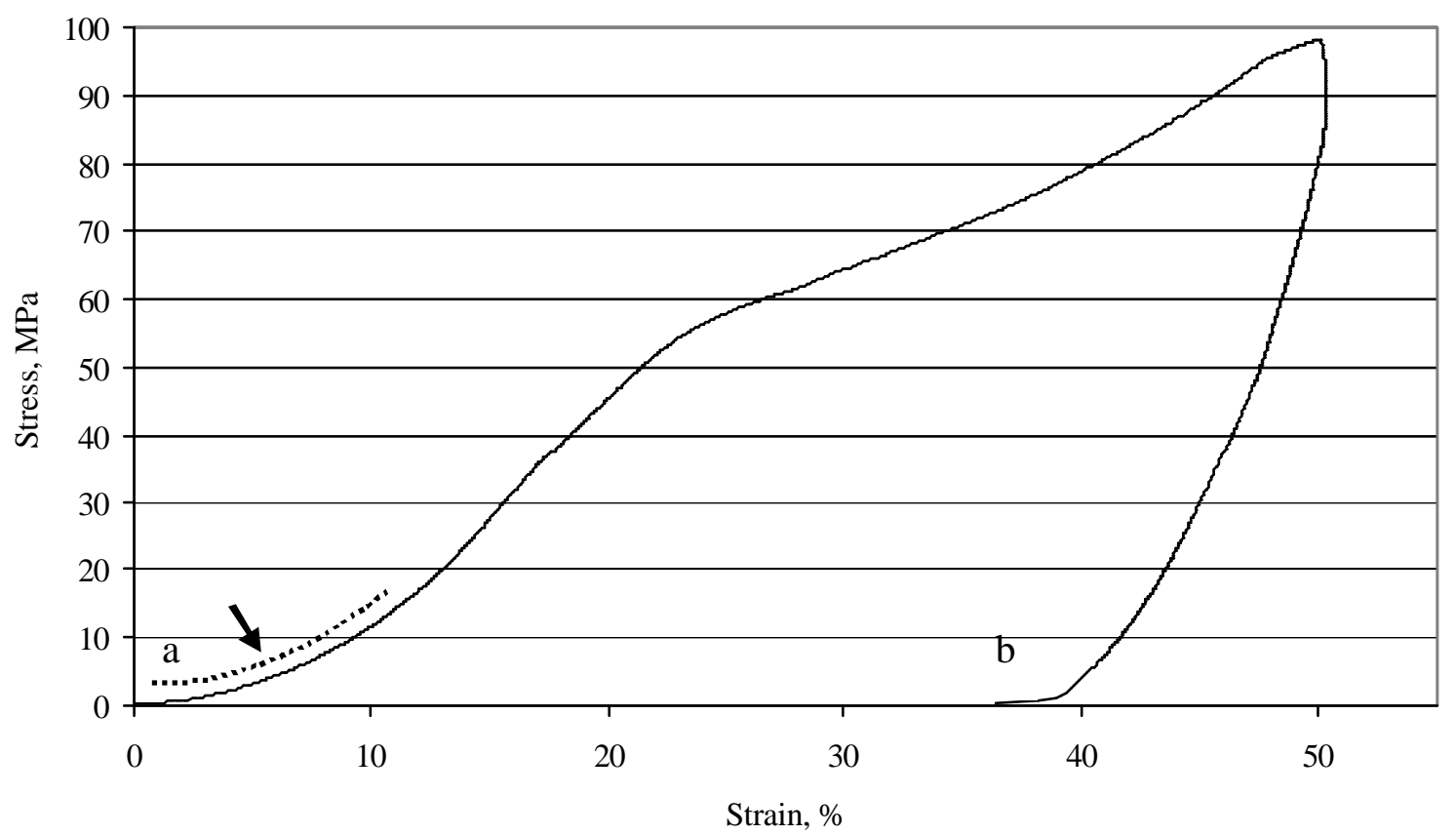

Fig. 6. Stress-strain diagram of bulb horn for loading and unloading (yield point $=47 \mathrm{MPa}$ ); note the slope (arrow) of the initial segment of the curve and its tangent line (' $a$ ') 


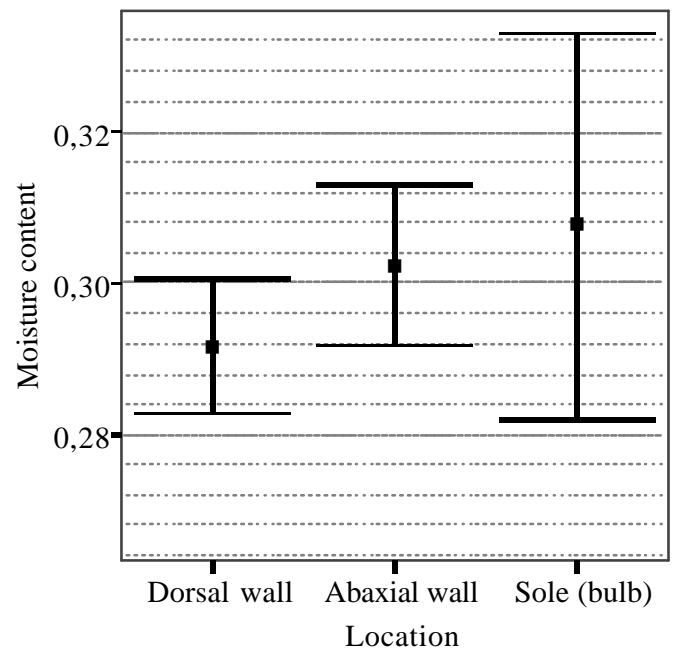

Fig. 7. Moisture content in the various horn segments (error bars: 95\% confidence interval for mean) 


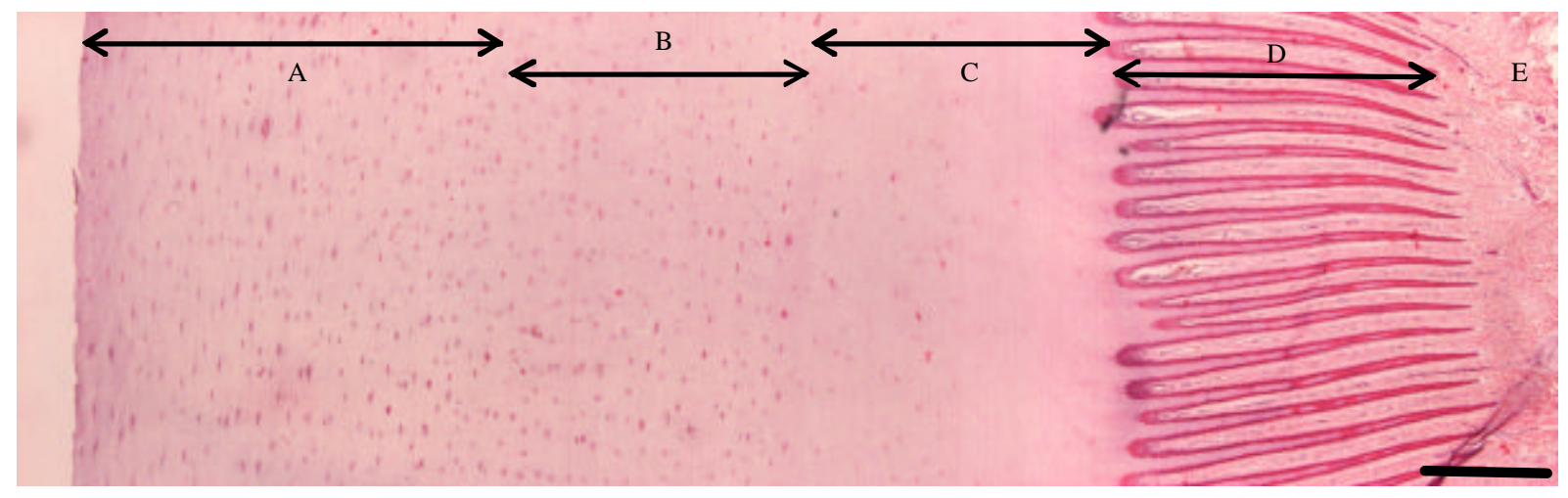

Fig. 8. Histological section of the abaxial claw wall (A, superficial zone with flattened tubules; $B$, intermediate zone with round to oval tubules; $C$, internal zone without tubules; $D$, parietal lamellar zone; , dermis; bar $=500 \mu \mathrm{m})$ 


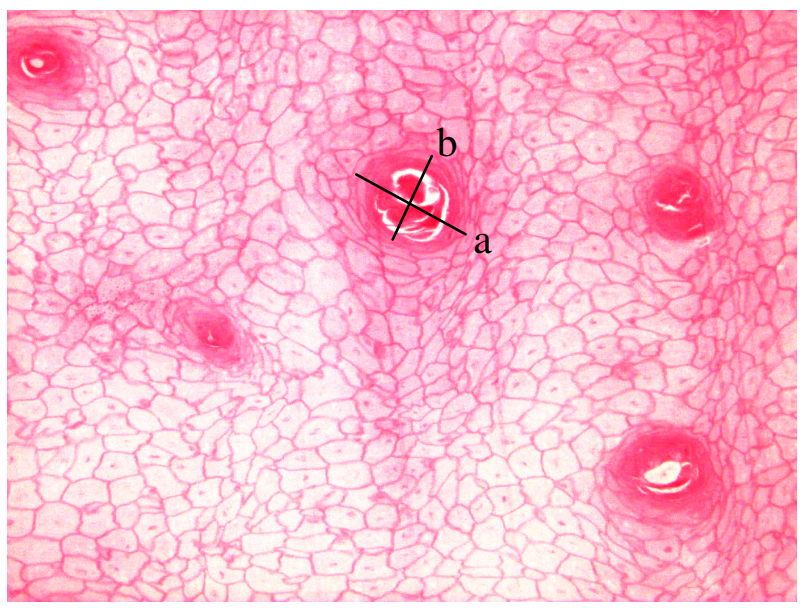

Fig. 9. Histological section of the bulb horn perpendicular to the long axis of the horn tubule ( $a$, large tubular diameter; $b$, small tubular diameter; $b a r=100 \mu m)$ 